\title{
Effect of the antioxidant "Bisphenol-5" on the digestibility of nutrients in the diet of broilers
}

\author{
Valentin Shilov ${ }^{1, *}$, Guzaliya Khakimova $^{1}$, Olga Semina $^{2}$, Renat Akhmadullin ${ }^{3}$ and Alfiia Akhmadullina ${ }^{3}$ \\ ${ }^{1}$ Tatar Institute of retraining personals of agrobusiness, 420059 Kazan, Russia \\ ${ }^{2}$ Biomir, 420081 Kazan, Russia \\ ${ }^{3}$ Akhmadullina A.G. private entrepreneur, Kazan, Russia
}

\begin{abstract}
The addition of the antioxidant "Bisphenol-5" in the dietary feed of broiler chickens in the amount of $0.0002,0.0004,0.0008$ and $0.0015 \%$ of its weight contributed to the dietary nutrients digestibility enhancement, their absorbability and assimilation of nitrogen, calcium, phosphorus, which affected the increase in the intensity of animal growth. The effective dose application of the antioxidant under study in broiler raising is $0.0008 \%$ of feed weight. Feeding of mixed fodders enriched with antioxidant at the given dosage of the third experimental bird group increased the digestibility of organic matter by $4.28 \%$ ( $\leq 0.001)$, increased absorption of nitrogen, calcium, phosphorus by 1.07, 0.27, $0.2 \mathrm{~g}(\mathrm{p}$ $\leq 0.001)$ respectively and increased average daily live weight by $13.6 \%$ ( $\mathrm{p} \leq 0.001)$ compared with individuals in the control group.
\end{abstract}

\section{Introduction}

When growing birds, special attention should be paid to feeding. Full value poultry feeding is the most important part of the industrial technology of poultry production [1]. The high productivity of poultry depends on full value feeding, which affects the digestibility of nutrients and their use [2]. Balanced feeding and high-quality food contribute to the normalization of the digestive processes in birds, their growth and development [3]. The nature of feeding farm animals is the main factor that has a diverse impact on the functional and morphological variability of the animal organism. First of all, feeding has an impact on the digestive system of animals, which is directly related functionally to the processing and assimilation of feed. Subsequently, the influence extends to the organs and systems of the body involved in the absorption of nutrients. Thus, feeding affects the whole body of the animal as a whole, changing its external form and general state [4].

A new trend in animal and poultry farming is the use of antioxidants to speed up digestibility and eliminate the factors that negatively affect the productivity of animals and birds, increasing the role of other catalysts and regulators of digestive processes. In this regard, the possibility of using antioxidants in animal husbandry is sought by direct inclusion of them into animal diets, primarily birds. Therefore antioxidants can be added together with vitamins and other biologically active substances in the composition of premixes. The use of antioxidant as feed additives such as BHT, BHA, santochinum and diludin in poultry farming is believed to be the most acceptable $[5,6]$. However, the short list was the need to search for new, cheaper and more affordable antioxidants [7-9].

The present study was designed to determine the effect of the antioxidant "Bisphenol-5" in feeding broiler chickens on the digestibility of nutrients and the use of nitrogen, calcium and phosphorus in the body of a bird. The main active ingredient of the antioxidant "Bisphenol-5" is 4,4'-bis(2,6-di-tert-butylphenol).

\section{Material and research methods}

The experiments were conducted on 50 broiler chickens of the "Cobb 500" cross. At the age of 15 days, chickens with a live weight of 486-506 $\mathrm{g}$ were delivered to the laboratory. According to the live weight, the birds were divided into 5 groups, 10 heads in each group. The control group chickens were given complete feed ("Growth" and "Finish") according to age and feeding standards.

The birds of the first, second, third and fourth experimental groups in addition to the diet were getting the antioxidant "Bisphenol-5" in a dose of 0.0002, $0.0004,0.0008$ and $0.0015 \%$ by weight of the feed respectively.

During the experiment, the birds were in the same conditions of housing, watering and feeding, in accordance with the recommendations of VNITIP [10]. Every five days, animals were weighed with further adjustment of the specified feed.

The experience lasted 41 days of life. During the scientific farming experiment to study the effect of the feed additive "Bisphenol-5" on nutrient digestibility and

\footnotetext{
Corresponding author: shilovvn@yandex.ru
} 
the use of nitrogen, calcium and phosphorus by the body of the bird, in accordance with the recommendations of VNITIP [11], 34-day-old broiler chickens were formed five groups of four specimen each. The birds were kept in individual cages with free access to food and water. The preliminary period of experiment was 5 days, record - 5 days. Feed intake and excretion of litter were considered. The chemical composition of feed and litter was determined by generally accepted research methods [12].

The separation of the nitrogenous substances of the litter into the nitrogenous substances of the feces and urine was carried out according to the modified method of M.I. Diacov [13].

Statistical processing of the obtained results was performed by the method of variation statistics using Microsoft Excel [14, 15].

\section{Results and discussion}

Experimental group of birds had a high growth rate. By the end of the experiment, the live weight of the broilers of the control group and the chickens of the experimental groups that were getting the antioxidant "Bisphenol-5" in different doses was unequal (Table 1).

Table 1. Productivity of broiler chickens cross "KOBB-500"

\begin{tabular}{|l|c|c|c|}
\hline \multirow{2}{*}{ Group of animals } & \multicolumn{2}{|c|}{ Live weight, $\mathrm{g}$} & \multirow{2}{*}{ Average weight gain, $g$} \\
\cline { 2 - 4 } & $\begin{array}{c}\text { at the beginning of the } \\
\text { experiment }\end{array}$ & $\begin{array}{l}\text { at the end of the } \\
\text { experiment }\end{array}$ & $1950.6 \pm 20.84$ \\
\hline Control & $491.8 \pm 12.34$ & $2442.4 \pm 19.79$ & $1997.4 \pm 16.0^{*}$ \\
\hline 1st experimental & $505.9 \pm 9.43$ & $2503.3 \pm 24.36^{*}$ & $2118.0 \pm 20.55^{* *}$ \\
\hline 2nd experimental & $497.0 \pm 13.71$ & $2615.0 \pm 31.73^{* *}$ & $2215.4 \pm 23.99^{* * *}$ \\
\hline 3rd experimental & $492.6 \pm 6.06$ & $2708.0 \pm 28.53^{* * *}$ & $2037.3 \pm 12.76^{*}$ \\
\hline 4th experimental & $485.9 \pm 13.57$ & $2523.2 \pm 23.01^{*}$ & \\
\hline
\end{tabular}

Note $^{*}-\mathrm{p} \leq 0.05 ; * *-\mathrm{p} \leq 0.01 ; * * *-\mathrm{p} \leq 0.001$

The analysis of the data given in Table 1 indicates that at the beginning of the experiment, the live weight of broiler chickens from the control and experimental groups differed slightly and the difference between the groups was not significant. Before slaughter, the birds of the experimental groups exceeded in live weight by 2.5$10.9 \%(\mathrm{p} \leq 0.05)$ specimen of the control group. Moreover, the growth rate of chickens is directly proportional to the dosage of the fed antioxidant. During the experiment, the average daily gain in live weight of broiler chickens in the control group was 75.01, in the first experimental group -76.82 ; in the second -81.46 ; in the third -85.21 and in the fourth $-78.36 \mathrm{~g}$, i.e. the birds of the experimental groups in this indicator reliably exceeded the specimen of the control group, respectively, by $2.4 ; 8.6 ; 13.6$ and $4.5 \%$.

The growth rate of birds also depends on the amount of absorbed nutrients of the diet, which are determined in the experiment of digestibility. The results of this experiment are presented in table 2 .
While studying the digestibility of nutrients in broiler chickens it was found that the use of the antioxidant "Bisphenol-5" in poultry feeding had a positive effect on the number of monomers absorbed through the wall of the digestive tract. The concentration of the antioxidant in the feed was influenced on the digestibility of nutrients in the diet differently (Table 2).

The highest coefficients of digestibility of dry matter were observed with the inclusion of antioxidant in the amount of $0.0008 \%$ of its mass. In the third experimental group, it was exceeded the similar indicator of poultry in the control group by $4.75 \%(\mathrm{p} \leq 0.001)$. Reducing the amount of added antioxidant to $0.0002 \%$ in the feed of broilers of the first experimental group caused an increase in the digestibility of all nutrients compared with specimen of the control group. However, the difference between the groups was insignificant, while the difference in protein and fiber was not significant.

Table 2. Estimation of nutrient digestibility of feed in broiler chickens

\begin{tabular}{|c|c|c|c|c|c|}
\hline \multirow{2}{*}{ Indicator } & \multicolumn{5}{|c|}{ Group } \\
\cline { 2 - 6 } & Control & $1^{\text {st }}$ experimental & $2^{\text {nd }}$ experimental & $\begin{array}{c}3^{\text {rd }} \\
\text { experimental }\end{array}$ & $\begin{array}{c}4^{\text {th }} \\
\text { experimental }\end{array}$ \\
\hline Dry matter & $70.19 \pm 0.67$ & $72.01 \pm 0.15^{*}$ & $73.80 \pm 0.17 * *$ & $74.94 \pm 0.25^{* * *}$ & $73.09 \pm 0.29 * *$ \\
\hline Organic matter & $72.84 \pm 0.61$ & $74.67 \pm 0.13^{*}$ & $76.53 \pm 0.15^{* *}$ & $77.12 \pm 0.23 * * *$ & $75.76 \pm 0.26^{* *}$ \\
\hline Protein & $89.98 \pm 0.22$ & $90.14 \pm 0.71$ & $91.35 \pm 0.06^{* *}$ & $91.74 \pm 0.08^{* * *}$ & $90.53 \pm 0.10$ \\
\hline Cellulose & $37.83 \pm 1.38$ & $40.89 \pm 2.18$ & $43.31 \pm 0.38^{* *}$ & $46.01 \pm 0.55^{* * *}$ & $41.54 \pm 0.63 *$ \\
\hline Fat & $89.26 \pm 0.24$ & $93.66 \pm 0.03^{* * *}$ & $92.19 \pm 0.05^{* * *}$ & $93.21 \pm 0.07 * * *$ & $90.70 \pm 0.10^{* *}$ \\
\hline BEV & $66.44 \pm 0.75$ & $68.33 \pm 0.17^{*}$ & $71.07 \pm 0.19 * * *$ & $71.40 \pm 0.28^{* * *}$ & $70.60 \pm 0.31^{* *}$ \\
\hline
\end{tabular}

Note $*-p \leq 0.05 ; * *-p \leq 0.01 ; * * *-p \leq 0.001$ 
The addition of the studied antioxidant to the mixed feed of broilers in a concentration of $0.0015 \%$ of its mass led to an improvement in the digestibility of nutrients compared to the control. However, the digestibility coefficients in birds of the fourth experimental group were at the level of the second experimental group, the specimen of which were supplemented with "Bisphenol-5" in a dose of $0.0004 \%$ of the feed weight.

Thus, the inclusion of the antioxidant "Bisphenol-5" in a dose of $0.0008 \%$ of its mass in the complete feed was contributed to the maximum increase in digestibility and absorption of dietary nutrients through the wall of the gastrointestinal tract. The coefficient of digestibility of organic matter in birds of the third experimental group was $77.12 \%$, which is $4.28 \%(\mathrm{p} \leq 0.001)$ more compared to the specimen in the control group.

Feeding of the growing broiler chickens should contribute to obtaining the maximum amount of products with rational use of the nutrients contained in the diet. When growing broiler chickens, nutrition should help to maximize production while rationally using the nutrients in the diet. The results of the balance experiment are shown in Table 3.

Table 3. Daily balance of nitrogen, calcium and phosphorus in experimental chickens ( $\mathrm{g}$ )

\begin{tabular}{|c|c|c|c|c|c|c|}
\hline \multirow{2}{*}{\multicolumn{2}{|c|}{ Indicator }} & \multicolumn{5}{|c|}{ Group } \\
\hline & & Control & $1^{\text {st }}$ experimental & $2^{\text {nd }}$ experimental & $3^{\text {rd }}$ experimental & $4^{\text {th }}$ experimental \\
\hline \multirow{7}{*}{ 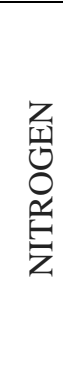 } & Received & $5.00 \pm 0.05$ & $5.18 \pm 0.08$ & $5.41 \pm 0.03 * * *$ & $6.10 \pm 0.03 * * *$ & $5.35 \pm 0.01 * * *$ \\
\hline & Stored with feces & $0.50 \pm 0.05$ & $0.51 \pm 0.01$ & $0.47 \pm 0.01 *$ & $0.50 \pm 0.01$ & $0.51 \pm 0.01$ \\
\hline & Digested & $4.50 \pm 0.05$ & $4.67 \pm 0.07$ & $4.94 \pm 0.03 * * *$ & $5.59 \pm 0.02 * * *$ & $4.84 \pm 0.01 * * *$ \\
\hline & Excreted in urine & $1.33 \pm 0.01$ & $1.39 \pm 0.01 * *$ & $1.46 \pm 0.02 * * *$ & $1.36 \pm 0.02$ & $1.2 \pm 0.02 *$ \\
\hline & Deposited in the body & $3.17 \pm 0.05$ & $3.28 \pm 0.06$ & $3.48 \pm 0.02 * *$ & $4.24 \pm 0.01 * * *$ & $3.59 \pm 0.01 * * *$ \\
\hline & $\begin{array}{l}\text { Utilization rate from } \\
\text { accepted, } \%\end{array}$ & $63.40 \pm 0.48$ & $63.28 \pm 0.19$ & $64.28 \pm 0.23$ & $69.50 \pm 0.31 * * *$ & $67.09 \pm 0.35 * * *$ \\
\hline & $\begin{array}{l}\text { Utilization ratio from } \\
\text { digested, \% }\end{array}$ & $70.46 \pm 0.38$ & $70.20 \pm 0.17$ & $70.36 \pm 0.21$ & $75.76 \pm 0.26 * * *$ & $74.11 \pm 0.31 * * *$ \\
\hline \multirow{4}{*}{$\begin{array}{l}\Sigma \\
己 \\
己 \\
\Xi \\
\Xi\end{array}$} & Received & $1.35 \pm 0.02$ & $1.41 \pm 0.02$ & $1.47 \pm 0.01 * * *$ & $1.68 \pm 0.01 * * *$ & $1.46 \pm 0.01 * * *$ \\
\hline & Stand out with droppings & $0.92 \pm 0.01$ & $0.91 \pm 0.01$ & $0.97 \pm 0.01 *$ & $0.98 \pm 0.01 *$ & $0.98 \pm 0.01 *$ \\
\hline & Assimilated & $0.43 \pm 0.01$ & $0.49 \pm 0.01 *$ & $0.51 \pm 0.01 *$ & $0.70 \pm 0.01 * * *$ & $0.48 \pm 0.01 *$ \\
\hline & $\begin{array}{l}\text { Utilization rate from } \\
\text { accepted, } \%\end{array}$ & $31.77 \pm 0.81$ & $35.07 \pm 0.44 *$ & $34.45 \pm 0.41 *$ & $41.86 \pm 0.56^{* * *}$ & $32.98 \pm 0.70$ \\
\hline \multirow{4}{*}{ 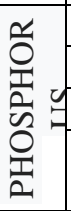 } & Received & $1.03 \pm 0.01$ & $1.07 \pm 0.02$ & $1.12 \pm 0.01 * * *$ & $1.26 \pm 0.01 * * *$ & $1.10 \pm 0.01 * * *$ \\
\hline & Stand out with droppings & $0.67 \pm 0.01$ & $0.68 \pm 0.01$ & $0.72 \pm 0.01 * * *$ & $0.68 \pm 0.01$ & $0.66 \pm 0.01$ \\
\hline & Assimilated & $0.37 \pm 0.01$ & $0.39 \pm 0.01$ & $0.39 \pm 0.01 *$ & $0.57 \pm 0.01 * * *$ & $0.45 \pm 0.01 * * *$ \\
\hline & $\begin{array}{l}\text { Utilization rate from } \\
\text { accepted, } \%\end{array}$ & $35.43 \pm 0.70$ & $36.46 \pm 0.32$ & $35.39 \pm 0.43$ & $45.68 \pm 0.55 * * *$ & $40.59 \pm 0.64 * *$ \\
\hline
\end{tabular}

Note $*-\mathrm{p} \leq 0.05 ; * *-\mathrm{p} \leq 0.01 ; * * *-\mathrm{p} \leq 0.001$

The important indicator reflecting the redox processes in the body is the nitrogen balance. Analysing the results of the research (Table 3), it was found that the daily nitrogen balance in the broilers of the control and experimental groups was positive. Feeding the chickens by the feed additive "Bisphenol-5" had a positive effect on nitrogen absorption. Moreover, with an increase in the concentration of the antioxidant in the mixed feed to $0.0008 \%$ of its mass, nitrogen retention in the body of specimen of the experimental groups increases.

Thus, adding "Bisphenol-5" in the amount of 0.0002 $\%$ of feed weight in the body of broilers deposited $3.28 \mathrm{~g}$ of nitrogen, which is $3.5 \%$ more in comparison with the birds of the control group. At optimum introduction of the antioxidant "Bisphenol-5", an average of $4.24 \mathrm{~g}$ of nitrogen was deposited in the body of the bird per day, which was $69.50 \%$ of that taken with feed and $75.76 \%$ of the digested $(\mathrm{p} \leq 0.001)$.

The inclusion of the antioxidant in the diet had a positive effect on poultry's appetite and feed intake. The degree of nitrogen retention in the body of the experimental bird group can be judged by the amount of its excretion with feces. In our observations, birds from the control and experimental groups with experiment masses isolated approximately the same amount of nitrogen (0.47-0.51 g). Meanwhile, the degree of retention of this element from the received one differed. Thus, the utilization rate of nitrogen in the first experimental group was 63.28 , in the second -64.28 , in the third -69.5 and in the fourth $-67.09 \%$ of the accepted.

It should be noted that an increase in the concentration of the studied additive to $0.0015 \%$ by weight of the mixed feed contributed to an increase of $13.2 \%(\mathrm{p} \leq 0.001)$ of nitrogen retention in the body of chickens compared to the peers of the control group.

Among the large group of minerals necessary for the full nutrition of broiler chickens, calcium and phosphorus play an especially important role.

The analysis of the data presented in Table 3 showed that the use of the antioxidant in feeding broiler chickens had a significant effect on calcium absorption. 
When studying the absorption of calcium by the poultry organism, it was found that increasing the dose of antioxidant feeding increased the retention of calcium in the body of the chickens of the experimental groups. Thus, the introduction of the antioxidant "Bisphenol-5" in the amount of $0.0002 \%, 0.0004,0.0008$ and $0.0015 \%$ by weight of the mixed feed contributed to an increase in calcium retention in the body, respectively, by 0.06 ( $\mathrm{p} \leq$ $0.05) ; 0.08(\mathrm{p} \leq 0.05) ; 0.27(\mathrm{p} \leq 0.001)$ and $0.05 \mathrm{~g}(\mathrm{p} \leq$ 0.05) compared with the specimen in the control group. As for the degree of retention of this element from that taken with feed, it depended both on the amount of calcium that came with the food and on its excretion from the body with droppings.

Analysing the results of the study, presented in table 3 , it was found that the daily balance of phosphorus in the body of broiler chickens of the control and experimental groups was positive.

The retention of phosphorus in the body of chickens depended both on the concentration of the antioxidant included into the mixed feed, and on the amount of this element received with the diet, as well as on the amount of the macro-element excreted with the droppings. In connection with the improvement of poultry appetite in broilers of the experimental groups that additionally received the additive "Bisphenol-5" in the dose of $0.0002,0.0004,0.0008$ and $0.0015 \%$ by weight of the mixed feed, the amount of phosphorus obtained from the feed increased respectively by $0.04,0.09,0.23$ and 0.07 g compared with the control.

The excretion of phosphorus with droppings in broilers of the control and experimental groups ranged from 0.66 to $0.72 \mathrm{~g}$. Moreover, the greatest excretion of this element with the droppings was observed in chickens from the second experimental group that were added an additive in the feed at a dose of $0.0004 \%$ of its mass.

Phosphorus was best used by broilers of the third experimental group that was getting in addition to the basic diet of the antioxidant "Bisphenol-5" in the amount of $0.0008 \%$ of the feed weight. The deposition of phosphorus in the body of birds in this group was $0.2 \mathrm{~g}$ more $(p \leq 0.001)$ compared with the specimen in the control group. The degree of use of this element from the feed received was also higher, and the difference was $10.25 \%(\mathrm{p} \leq 0.001)$ compared with the control.

\section{Conclusion}

Thus, the studies have shown that feeding, enriched with "Bisphenol-5" in different concentrations, had a significant impact on increasing the digestibility of feed nutrients and improving the assimilation of nitrogen in the diet, on calcium retention in the body of the bird, as well as on the intensity of phosphorus metabolism in the body of broiler chickens, and, ultimately, all this was reflected in the acceleration of the growth processes of the bird. The best results for these indicators were observed when the antioxidant was added in the feed at a dose of $0.0008 \%$ of its mass.

\section{References}

1. N.G. Makartsev, Feeding of farm animals (Noosphere, Kaluga, 2012)

2. E.S. Dzetseva, The effectiveness of the use of rations enriched with lactic whey in the feeding of broilers and laying hens $\mathrm{PhD}$ dissertation thesis (Gorskiy state agrarian university of Vladikavkaz, 2000)

3. Yu.M. Stepanov, Comp. New in poultry farming (Moskovskiy rabochiy, Moscow, 1987)

4. Yu.A. Tolokonnikov, A.V. Tishchenko, Feeding of farm animals in industrial animal husbandry (Kolos, Leningrad, 1978)

5. L.M. Dvinskaya, A.A. Subin, The use of antioxidants in animal husbandry (Agropromizdat, Leningrad, 1986)

6. L.P. Zaripova, G.I. Shakirova, Feed virtues of alfalfa (Kazan, 1984)

7. M.A. Kustov, The effect of the antioxidant dinofen on productivity, quality of meat and chicken eggs during stress $\mathrm{PhD}$ dissertation thesis (Voronezh, 2001)

8. V.N. Shilov, G.A. Khakimova, O.V. Semina, R.M. Akhmadullin, Growth processes of broiler chickens when they are fed with the antioxidant Bisphenol-5 in Probl. of innovat. Developm. of the agroindustrial complex: personnel, technology, efficiency 11, 320-324 (Kazan, 2017)

9. G.A. Khakimov, V.N. Shilov, R.M. Akhmadullin, A.G. Akhmadullina, O.V. Semina, Influence of antioxidant on blood parameters of broiler chickens Poultry farming 8, 42-47 (2018)

10. B.V. Balobin, I.B. Izmailovich, Poultry farming (Gorki BSAA, 2007)

11. E.A. Petukhova, R.F. Bessarabova, L.D. Haleneva et al., Zootechnical analysis of feed (Agropromizdat, Moscow, 1989)

12. I.A. Egrov, The methodology of conducting scientific and industrial research on feeding poultry 51 (RRTIP, Sergiev Posad, 2013)

13. A.I. Ovsyannikov, Fundamentals of experimental business in animal husbandry 154-155 (Kolos, Moscow, 1976)

14. G.F. Lakin, Biometrics. Textbook 352 (Higher School, Moscow, 1990)

15. V.P. Leonov, P.V. Izhevsk, On the use of applied statistics in the preparation of dissertations in medical and biological specialties Bull. HAC RF 5, 56-61 (1997) 